\section{Monkey see}

\section{By Michael J. Haas, Senior Writer}

U.S. researchers have cured red-green color blindness in monkeys using gene therapy. ${ }^{1}$ Although the group is unsure about the risk-benefit ratio of treating color blindness in humans, team members are investigating whether the approach can treat more severe vision disorders.

Most untreatable vision disorders are caused by genetic defects that result in improper functioning of the photoreceptors in the retina. In disorders such as cone dystrophy, cone-rod dystrophy and early onset macular degeneration, genetic mutations induce abnormal protein expression that damages the retina, resulting in loss of vision.

In red-green color blindness, the retina is healthy but lacks either red light- or green light-sensitive photopigments because of a defect in one of the genes encoding those pigments. The defect can be in either the opsin 1 (cone pigments) long-wavesensitive (OPN1LW) gene or the opsin 1 (cone pigments) medium-wave-sensitive (OPN1MW) gene, which code for red and green light-sensitive cone photopigments, respectively.

Researchers at the University of Washington and colleagues wanted to know whether gene therapy could restore missing photoreceptor components to an otherwise healthy retina. They chose red-green color blindness as a test case because it is the most common congenital vision disorder in humans.

"This study allowed us to assess the potential of adding something to the healthy retina" to correct a genetic defect and thereby treat or cure a congenital condition, team coleader Jay Neitz told SciBX. Neitz is professor of ophthalmology at the University of Washington.

The team was co-led by Maureen Neitz, who is professor of ophthalmology at the University of Washington, and included scientists from the University of Florida College of Medicine and the Medical College of Wisconsin.

The group treated color-blind, adult squirrel monkeys with subretinal injections of an adeno-associated viral (AAV) vector that encoded recombinant human OPN1LW. After 20 weeks, the treated monkeys had high OPN1LW expression in the retina and a concomitant increase in red-green color perception compared with untreated controls.

The color perception of treated color-blind monkeys was comparable to that of control monkeys with normal vision. The team studied squirrel monkeys (Saimiri sciureus) because their color blindness has the same genetic cause as that in humans. Results were published in Nature. ${ }^{1}$
"We didn't really get into this to cure color blindness," but rather to cure genetic disorders that cause loss of vision, said Jay Neitz. "In that sense, curing color blindness is almost identical to what we'd have to do to cure blindness, and I see our work as a major step forward in that direction."

Indeed, the team has already extended the approach to treating congenital achromatopsia, a disease in which patients see very poorly because of complete lack of color vision.

According to Neitz, about $95 \%$ of all the photoreceptors in a normal human eye are red- or green-light sensitive. Thus, achromatopsia patients are blind due to an almost complete lack of light-sensitive photoreceptors. "Presumably our method could treat achromatopsia" by restoring the missing or defective photoreceptor components to the healthy retina, he said.

The team is testing the gene therapy in a mouse model of achromatopsia.

Neitz did say he hasn't ruled out the possibility of developing the gene therapy approach to treat red-green color blindness in humans.

Due to numerous phone calls received from color-blind individuals in response to the Nature study, "I have gained a lot of sympathy and sensitivity" for people with the condition, he said. "I think it is possible that this approach could cure color blindness in humans."

Nevertheless, he said it was not yet clear whether the risk-benefit ratio is acceptable for that indication. "If a person is completely blind, the benefit of this therapy is so great that it might outweigh the risks," he said. "But in color-blind people, $100 \%$ safety is important" because those individuals have otherwise healthy eyes and normal vision.

Neitz noted that the gene delivery method, which was developed by his coauthor on the Nature paper, William Hauswirth, is in a Phase I/II trial to treat retinal degeneration and appears to be safe. Applied Genetic Technologies Corp. is running that trial.

Hauswirth is a professor of ophthalmology and molecular genetics at the University of Florida College of Medicine and a cofounder of Applied Genetic Technologies.

The company's rAAV2-CB-hRPE65, an AAV vector encoding the human RPE65 (retinal pigment epithelium-specific protein $65 \mathrm{kDa}$ ) gene, is in Phase I/II testing to treat type 2 Leber's congenital amaurosis (LCA). LCA is a form of retinal degeneration caused by defects in 1 of 11 of the genes known to contribute to the disease. The condition causes complete loss of vision by the time a patient reaches adulthood.

Neitz said the University of Washington team has filed provisional patent applications covering the therapeutic genes used in the Nature study but noted that the gene delivery method is covered by existing patents that are owned by The University of Florida Research Foundation Inc.

Susan Washer, CEO of Applied Genetic Technologies, confirmed that the company licenses the gene delivery technology used in its LCA clinical trial from the foundation. 


\section{TARGETS \& MECHANISMS}

Said Neitz: "We are absolutely interested in finding partners to help develop these findings."

Haas, M.J. SciBX 2(37); doi:10.1038/scibx.2009.1395

Published online Sept. 24, 2009

REFERENCES

1. Mancuso, K. et al. Nature; published online Sept. 17, 2009; doi:10.1038/nature0840
Contact: Jay Neitz, University of Washington, Seattle, Wash. e-mail: jneitz@uw.edu

COMPANIES AND INSTITUTIONS MENTIONED

Applied Genetic Technologies Corp., Alachua, Fla.

Medical College of Wisconsin, Milwaukee, Wis.

University of Florida College of Medicine, Gainesville, Fla.

The University of Florida Research Foundation Inc., Gainesville, Fla.

University of Washington, Seattle, Wash. 